\title{
A sensitive, rapid and validated liquid chromatography - tandem mass spectrometry (LC-MS-MS) method for determination of Mimosine in Mimosa pudica Linn
}

\author{
Parikshit A. Champanerkar $^{1 *}$, Vikas V. Vaidya ${ }^{1}$, Sunita Shailajan ${ }^{1}$, Sasikumar N. Menon ${ }^{2}$ \\ ${ }^{1}$ Department of Chemistry, Ramnarain Ruia College, Mumbai University, Mumbai, India; \\ *Corresponding Author: parikshit ac@indiatimes.com \\ ${ }^{2}$ Therapeutic Drug Monitoring Laboratory, Sion Koliwada, Mumbai, India
}

Received 28 March 2010; revised 24 May 2010; accepted 2 June 2010.

\begin{abstract}
A rapid, sensitive and accurate liquid chromatographic tandem mass spectrometric method is described for the determination of Mimosine in Mimosa pudica Linn. whole plant powder. Mimosine was extracted from the plant using $1.0 \%$ $\mathrm{HCl}$ in water. The chromatographic separation was achieved using a Thermo Hypurity C18 (50 x $4.6 \mathrm{~mm}) 5.0 \mu$ column interfaced with a triple quadrapole mass spectrometer. The mobile phase consisted of a mixture of Methanol: 10 $\mathrm{mM}$ ammonium formate buffer whose $\mathrm{pH}$ was adjusted to $3.00 \pm 0.05$ with formic acid $(80: 20$, $\mathrm{v} / \mathrm{v}$ ) and was delivered at a flow rate of $1.0 \mathrm{~mL}$ $\mathrm{min}^{-1}$. Electrospray ionization (ESI) source operated in the negative ion mode was used for the quantitation. Detection was performed using an Applied Biosystems Sciex API 3200 Mass spectrometer. The method was found to be simple, precise, accurate, fast, specific and sensitive and can be used for routine quality control analysis of Mimosine in Mimosa pudica Linn.
\end{abstract}

Keywords: LC-MS-MS; Mimosine; Mimosa pudica Linn

\section{INTRODUCTION}

Mimosa pudica Linn. (Fam. -Leguminosae) is commonly known as Sensitive plant in English and Lajvanti or Chuimui in Hindi language. The plant is distributed through out India especially in moist places. Mimosa pudica Linn. is also said to have larvicidal property [1]. It is used to treat menorrhagia and leucorrhoea [2-4]. In Ayurvedic system of medicine, Mimosa pudica Linn. has been described as an indispensable drug for blood pres- sure [5]. Phytochemical screening has revealed that the plant contains Mimosine (alkaloid), stigmasterol, leucoanthocyanidin, D-xylose and D-glucuronic acid, norepinephrine, D-pinitol, linoleic acid, oleic acid, palmitic acid, stearic acid, $\beta$-sitosterol and crocetin dimethyl ester. Of all these, the major compound present in Mimosa pudica Linn. is Mimosine [4]. Mimosine is used for treating the cutaneous effects of psoriasis and related skin disorders [6]. It is less soluble in methanol and ethanol, insoluble in other organic solvents, but sparingly soluble in water. It is soluble in dilute acid and base. Structure of Mimosine is shown in Figure 1 [7].

The quality of herbal medicine that is the profile of the constituents in the final product has implication in efficacy and safety. Due to the complex nature and inherent variability of the chemical constituents of the plant based drugs, it is difficult to establish quality control parameters and modern analytical techniques are accepted to help in circumventing this problem [8]. Recently, the concept of marker-based standardization of herbal drugs is gaining momentum. Identification of major and unique compounds in herbs as markers and development of analytical methodologies for monitoring them are the key steps involved in marker-based standardization [9].

Quantitation of Mimosine from Mimosa pudica L. using RP-HPTLC has been reported [10]. A method using HPLC and spectrophotometric determination of Mimosine has also been reported $[11,12]$. Literature survey, hence, revealed that there is no method available in the

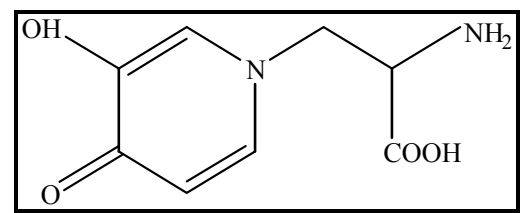

Figure 1. Structure of Mimosine. 
public domain for quantitation of Mimosine from $\mathrm{Mi}$ mosa pudica Linn. using an LC-MS-MS system. So, the aim of the present work was to develop a simple, fast, sensitive, precise, and accurate LC-MS-MS method for determination of Mimosine from Mimosa pudica L. The developed method was further validated as per $\mathrm{ICH}$ guidelines to indicate its suitability $[13,14]$.

\section{Experimental}

\subsection{Chemicals and Preparation of Standard Solutions}

HPLC grade Methanol and acetonitrile were purchased from J.T. Baker, Mumbai, India. Extra pure Formic acid (99.9\%) and ammonium formate was purchased from Fluka, Steinheim, Germany. High purity deionised water was prepared in-house using a Milli-Q water purification system obtained from Millipore, Bangalore, India. Mimosine standard (Purity 98\%) was procured from Sigma-Aldrich (Aldrich Division; Steinheim, Federal Republic of Germany).

The stock solution A of Mimosine $\left(1,000 \mu \mathrm{g} \mathrm{mL}^{-1}\right)$ was prepared by dissolving $25 \mathrm{mg}$ of accurately weighed Mimosine in minimum quantity of $1.0 \% \mathrm{HCl}$ in water and diluting with same solution up to the mark in a 25 $\mathrm{mL}$ standard volumetric flask. Further solution B of Mimosine $\left(10 \mu \mathrm{g} \mathrm{mL}^{-1}\right)$ was prepared by transferring $0.25 \mathrm{~mL}$ of stock solution A and diluting with mobile phase up to the mark in a $25 \mathrm{~mL}$ volumetric flask. Different volumes in the range of $0.4-1.0 \mathrm{~mL}$ of stock solution B were transferred to $10 \mathrm{~mL}$ standard volumetric flasks and diluted up to the mark with the mobile phase, to provide a concentration range of 400-1000 $\mathrm{ng} \mathrm{mL}^{-1}$.

\subsection{Plant Material and Preparation of Sample Solution}

The plant Mimosa pudica L. was collected from Mumbai, Maharashtra, India and was authenticated by National Institute for Science Communication and Information Resources (NISCAIR), New Delhi, India. The collected plant material was dried at room temperature, under shade and then ground in a mixer to a fine powder. This was then passed through an ASTM BSS mesh (size 85) and stored in an airtight container at room temperature. $25 \mathrm{mg}$ of the dried powder was accurately weighed, placed in a stoppered tube and $10 \mathrm{~mL}$ of Methanol was added. The sample was vortexed for 1-2 minutes and then mixed on a shaker for 60 minutes. The contents of the tube were then centrifuged at $4600 \mathrm{rpm}$ and filtered through Whatmann No. 41 filter paper (E. Merck, Mumbai, India) and residue was collected in a $10 \mathrm{~mL}$ standard volumetric flask and $1.0 \% \mathrm{HCl}$ in water was added up to the mark, the sample was vortexed for 1-2 minutes and left to stand overnight at room temperature. The content was filtered through Whatmann No. 41 filter paper and the clear supernatant was collected in a dry tube (solution C). Further solution D was prepared by transferring $1.0 \mathrm{~mL}$ of solution $\mathrm{C}$ and diluting with mobile phase up to the mark in a $10 \mathrm{~mL}$ volumetric flask. Solution D was used for further experiments.

\subsection{Instrumentation and Chromatographic Conditions}

A Hypurity $\mathrm{C}_{18},(50 \times 4.6 \mathrm{~mm}), 5 \mu$ obtained from Thermo Electron, Mumbai, India was used for the compound retention. The mobile phase consisted of mixture of Methanol: $10 \mathrm{mM}$ ammonium formate buffer $\mathrm{pH}$ adjusted to $3.00 \pm 0.05$ with formic acid $(80: 20, \mathrm{v} / \mathrm{v})$ and was delivered at a flow rate of $1.0 \mathrm{~mL} \mathrm{~min}^{-1}$ by employing a Shimadzu Prominence series (Kyoto, Japan) binary pump, at ambient temperature. Detection was achieved using an Applied Biosystems API 3200 MS-MS apparatus (Applied Biosystems, Ontario, Canada) fitted with a Turbo Ion Spray source. The instrument was interfaced with a computer running Applied Biosystems Analyst version 1.4.2 software. Electrospray ionization (ESI) was performed in the negative ion mode. The spray voltage and source temperature were $-4500 \mathrm{~V}$ and $550^{\circ} \mathrm{C}$ respectively. Nitrogen was used as the collision gas. The Declustering Potential (DP), Collision Energy (CE), Entrance potential (EP), Cell Exit Potential (CXP) were optimized during tuning as $-20,-24,-10,-4 \mathrm{eV}$ for Mimosine. The collision activated dissociation (CAD) gas was set at $3 \mathrm{psi}$, while the curtain gas was set at 12 psi. The Applied Biosystems API 3200 LC-MS-MS apparatus was operated at unit resolution in the multiple reaction monitoring (MRM) mode, monitoring the transition of the molecular ion $\mathrm{m} / \mathrm{z} 197.7$ to the product ion $\mathrm{m} / \mathrm{z} 162.8$ for Mimosine. The instrument response was optimized for Mimosine by infusing a constant flow of a standard solution $\left(1000 \mathrm{ng} \mathrm{mL} \mathrm{m}^{-1}\right)$ via a T-piece into the stream of mobile phase eluting from the column. Figure 2 shows the product ion mass spectra obtained from collision-induced dissociation of the deprotonated molecular ions of Mimosine.

\section{METHOD VALIDATION}

\subsection{System Suitability}

System suitability tests are used to ensure reproducibility of the equipment. The test was carried out by injecting $10 \mu \mathrm{L}$ of standard solution of Mimosine $\left(600 \mathrm{ng} \mathrm{mL}^{-1}\right)$ six times. The \% RSD was found to be $1.27 \%$ for $\mathrm{Mi}-$ mosine, which was acceptable as it is less than $2 \%$.

\subsection{Linearity}

In order to establish linearity, standard solutions of Mi- 


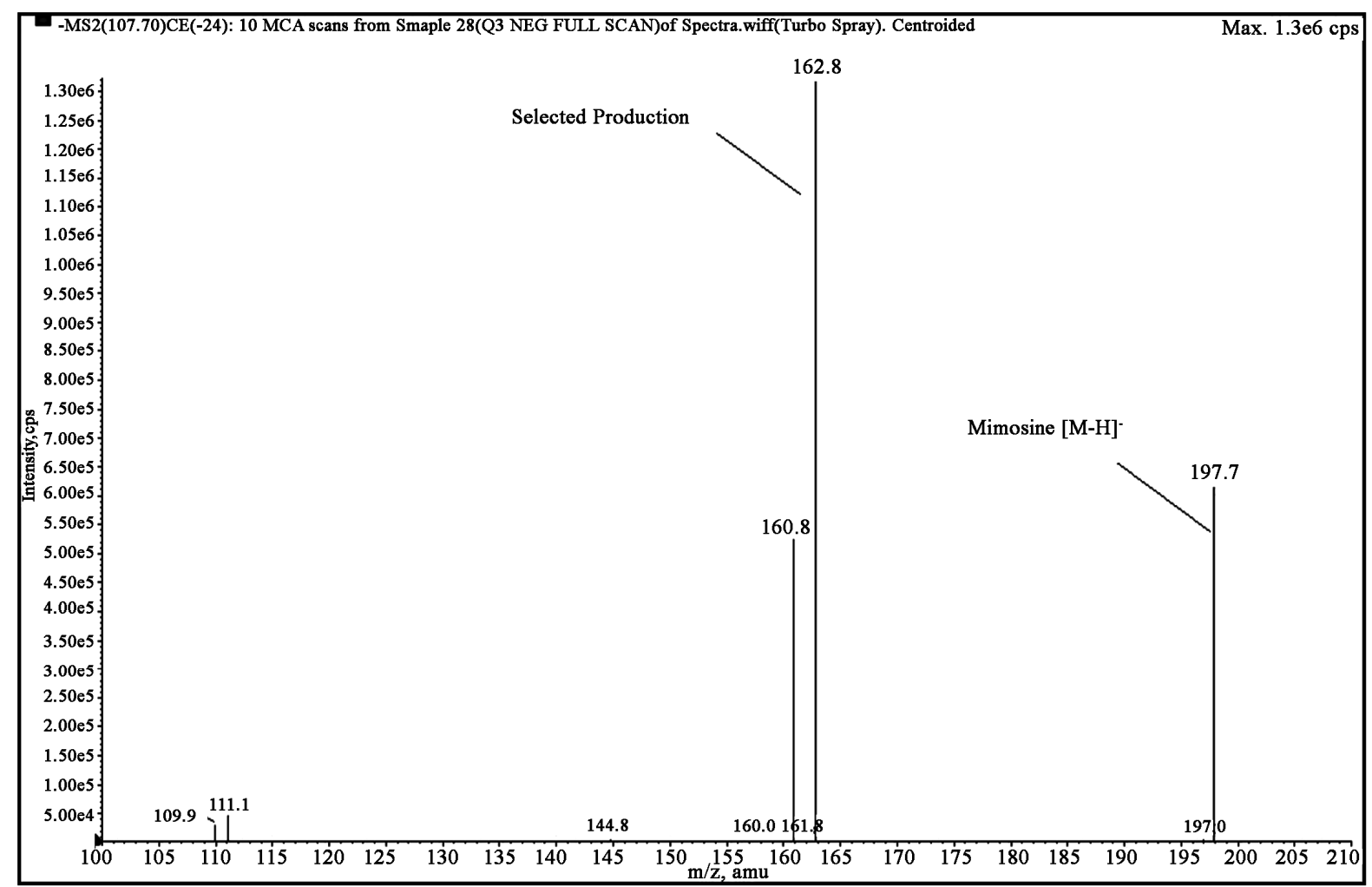

Figure 2. Representative Spectra of product ion of Mimosine.

mosine at six different concentrations $(400.0,5 \% 00.0$, 600.0, 700.0, 800.0 and $1000.0 \mathrm{ng} \mathrm{mL}^{-1}$ ) were prepared in mobile phase. Each of these solutions $(10 \mu \mathrm{L})$ was injected and the detector response for the different concentrations was measured. A graph was plotted of drug peak area against concentration. The plot was linear in the range $400.0 \mathrm{ng} \mathrm{mL}^{-1}$ to $1000.0 \mathrm{ng} \mathrm{mL}^{-1}$ for Mimosine. The experiment was performed five times and the mean was used for the calculations. The equation of linear regression curve obtained was $\mathrm{y}=94.4 \mathrm{x}-1923.3$, where $\mathrm{y}$ $=$ (peak area), $\mathrm{x}=$ (concentration of Mimosine in ng $\mathrm{mL}^{-1}$ ) with a correlation coefficient 0.9951 . A typical chromatogram of standard and plant is shown in Figure 3 and Figure 4 respectively.

\subsection{Limit of Detection and Limits of Quan- titation}

The signal-to-noise ratio of 3:1 and 10:1 was used to establish LOD and LOQ, respectively. The LOD and LOQ of Mimosine were $100 \mathrm{ng} \mathrm{mL}^{-1}$ and $400.0 \mathrm{ng} \mathrm{mL}^{-1}$, respectively.

\subsection{Assay}

The developed LC-MS-MS method was used for determination of Mimosine from whole plant powder of $\mathrm{Mi}$ mosa pudica $L$. The sample working solution $\mathrm{D}(10 \mu \mathrm{L})$ was injected and the area of Mimosine peak was measured. From the calibration curve, the amount of Mimosine in dry powder of Mimosa pudica L. was calculated. The retention time of Mimosine in sample solution and in the standard solution was found to be $0.67 \mathrm{~min}$. The mean assay value of Mimosine was found to be $1.938 \mathrm{mg} / \mathrm{g}$ of plant powder with \% RSD as $1.55 \%$.

\subsection{Precision and Accuracy}

The intra-day and inter-day precision was used to study the variability of the method. The \% RSD for intra-day and inter-day precision for Mimosine were 0.66 and $1.06 \%$, respectively. Accuracy of the method was studied using the method of standard addition. Standard Mimosine solution were added to the extract of the whole plant powder of Mimosa pudica $\mathrm{L}$. and the percent recovery was determined at two different levels $50 \%$ and $100 \%$. Mimosine content was determined and the percent recovery was calculated. The results of recovery analysis are shown in Table $\mathbf{1}$.

\section{RESULTS AND DISCUSSION}

The high selectivity of MS-MS detection allowed the development of a very specific and rapid method for the determination of Mimosine in Mimosa pudica L. whole 
Table 1. Results of recovery experiment.

\begin{tabular}{|c|c|c|c|c|c|c|c|}
\hline Standard & Level & $\begin{array}{l}\text { Pre analysed } \\
\text { sample in } \\
\left(\mathrm{ng} \mathrm{mL} \mathbf{L}^{-1}\right)\end{array}$ & $\begin{array}{l}\text { Amount of std added } \\
\text { to pre analysed } \\
\text { sample in }\left(\mathrm{ng} \mathrm{mL} \mathbf{~}^{-1}\right)\end{array}$ & $\begin{array}{l}\text { Total amount of } \\
\text { std found in } \\
\left(\mathrm{ng} \mathrm{m} \mathbf{L}^{-1}\right)\end{array}$ & SD & $\begin{array}{c}\text { RSD (\%) } \\
(n=7)\end{array}$ & $\begin{array}{c}\text { Recovery } \\
(\%)\end{array}$ \\
\hline \multirow{4}{*}{ Mimosine } & 0 & 484.59 & 0 & 479.13 & 6.72 & 1.40 & 98.87 \\
\hline & $50 \%$ & 484.59 & 250 & 730.79 & 7.40 & 1.01 & 99.48 \\
\hline & $100 \%$ & 484.59 & 500 & 979.39 & 10.96 & 1.12 & 99.47 \\
\hline & & & & & & Mean & 99.28 \\
\hline
\end{tabular}

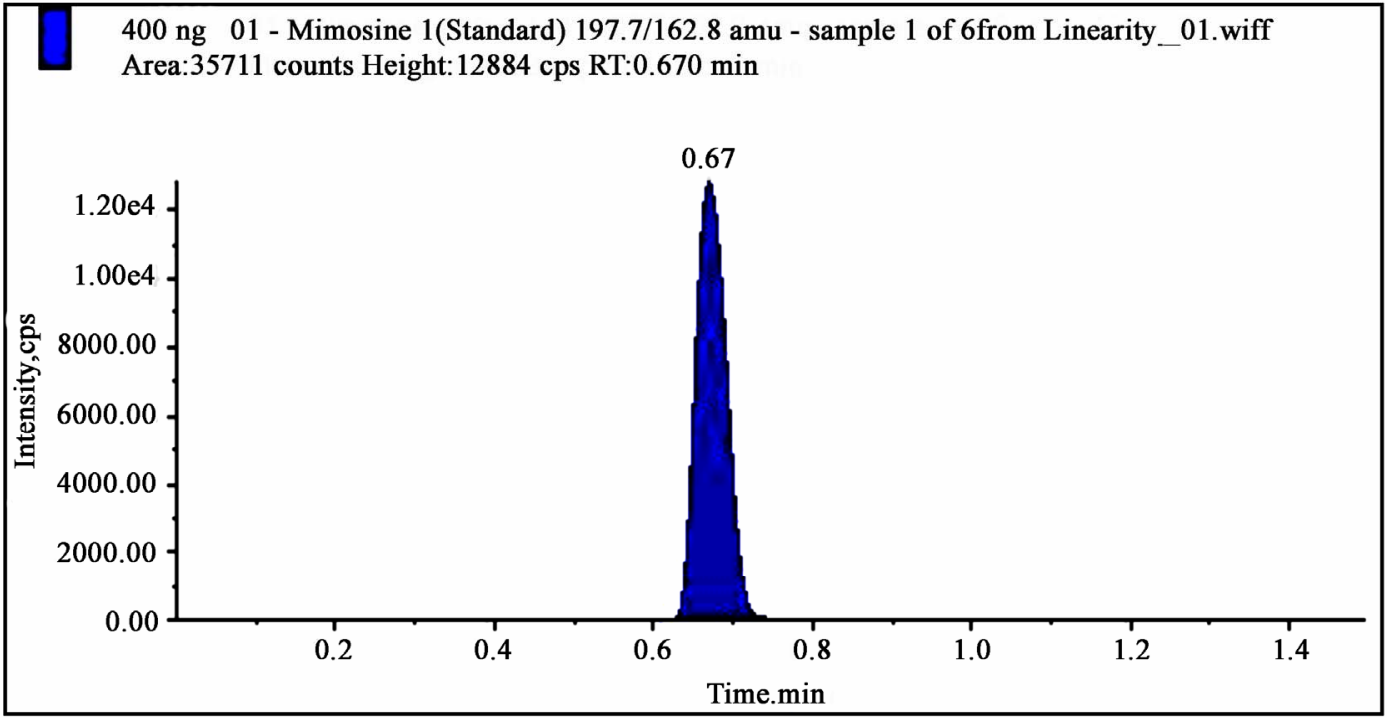

Figure 3. Representative chromatogram of standard Mimosine at LLOQ level (400 $\left.\mathrm{ng} \mathrm{mL} \mathrm{m}^{-1}\right)$.

Plant_01 - Mimosine 1(Unknown) 197.7/162.8 amu - sample 1 of 7 from Assay_01.wiff Area:44214 counts Height:14418 cps RT:0.674 min

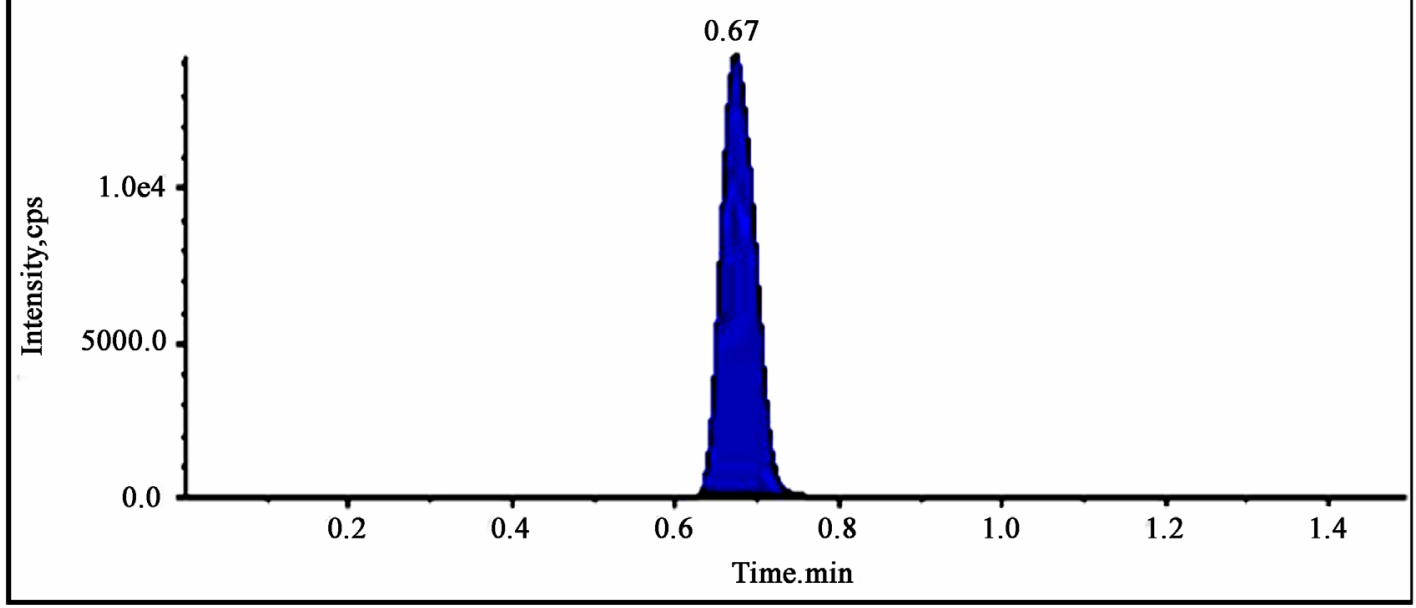

Figure 4. Representative chromatogram of plant Mimosa pudica L.

plant powder. During method development different options were evaluated to optimize, detection parameters and chromatography. Electrospray ionization (ESI) was evaluated to get better response of analytes as compared to atmospheric pressure chemical ionization (APCI) mode. It was found that the best signal was achieved 
with the ESI negative ion mode. A mobile phase containing formic acid solution and Methanol in varying combinations was tried during the initial development stages. But the best signal for Mimosine was achieved using a mobile phase containing $10 \mathrm{mM}$ ammonium formate buffer $\mathrm{pH}$ adjusted to $3.00 \pm 0.05$ with formic acid in combination with Methanol $(20: 80 \mathrm{v} / \mathrm{v})$. Use of a short Hypurity $\mathrm{C}_{18},(50 \mathrm{~mm} \times 4.6 \mathrm{~mm}), 5 \mu$ column resulted in reduced run time of $1.5 \mathrm{~min}$. Regression analysis of calibration data showed that the linearity of Mimosine was observer over a concentration range of 400 $\mathrm{ng} \mathrm{mL} \mathrm{m}^{-1}$ to $1000 \mathrm{ng} \mathrm{mL} \mathrm{L}^{-1}$ with regression coefficient of 0.9951. The concentration of Mimosine in $1.0 \mathrm{~g}$ of whole plant powder of Mimosa pudica L. was found to be $1.938 \mathrm{mg}$.

When the method was validated in terms of instrumental precision, intra-assay precision and intermediate precision, the percent RSD values were found to be less then 2 , indicating that the proposed method is precise and reproducible. The accuracy of the method was established by means of recovery experiments. The mean recovery was close to $100 \%$, which indicates that method is accurate. The low values of $\% \mathrm{COV}$ for replicate analyses are indicative of precision of the method. The method is specific because it resolved the standard Mimosine (Retention time $=0.67$ ) well in presence of other phytochemicals of whole plant powder of Mimosa pudica $\mathrm{L}$.

\section{CONCLUSIONS}

A new LC-MS-MS method has been developed for quantification of Mimosine from whole plant powder of Mimosa pudica L. The method developed with careful validation was found to be fast, simple, precise, sensitive and accurate. The linearity, precision, accuracy of the method prove that the method is easily reproducible in any quality control set-up provided all the parameters are followed accurately.

\section{REFERENCES}

[1] Sharma, S.K. and Wattal, B.L. (1979) Efficacy of some mucilaginous seeds as biological control agents against mosquito larvae. Journal of the Entomological Research, 3(2), 172-176.

[2] Vaidya, G.H. and Sheth, U.K. (1986) Mimosa pudica Linn., its medicinal value and pilot clinical use in patients with menorrhagia. Ancient Science of Life, 5(3), 156-160.

[3] Hemadri, K. and Rao, S.S. (1983) Leucorrhoea and Menorrhagia. Tribal Medicine and Ancient Science of Life, 3(1), 40-41.

[4] Sharma, P.C., Yelna, M.B. and Dennis, T.J. (2001) Database on medicinal plants used in Ayurveda. Central Council for Research in Ayurveda \& Siddha, India, 2, 369-379.

[5] Aalok, P.K. (1997) Lajjalu-an indispensable drug for blood pressure. Sachitra Ayurved, 50(1), 21-22.

[6] Zeitune, M.G. and Laguens, R.M., Inventors, Xl global corporation, assignee, use of mimosine or a derivative thereof for treating the cutaneous effects of psoriasis and related skin disorders, and cosmetic or pharmaceutical composition containing same. US patent 424725.

[7] (2006) The Mreck index. Mimosine, 14(6199), 1069.

[8] Bagul, M.S. and Rajani, M. (2005) Phytochemical evaluation of classical formulation: A case study. Indian Drugs, 42(11), 15-19.

[9] Debey, N., Debey, N., Mehta, R. and Saluja, A. (2009) Determination of psoralen and plumbagin from its polyherbal oil formulation by an HPTLC. Journal of AOAC International, 92(3), 779-784.

[10] Nair, L.S., Menon, S.N., Shailajan, S., Baing, M.M. and Sane, R.T. (2007) Reverse phase high performance thin layer chromatographic quantification of Mimosine from whole plant of Mimosa pudica Linn. Journal of Planer Chromatography-Modern TLC, 20(1), 49-51.

[11] Puchala, R., Davis, J.J. and Sahlu, T. (1996) Determination of mimosine and 3,4-dihydroxypyridine in milk and plasma of goats. Journal of Chromatography B: Biomedical Sciences and Applications, 685(2), 375378.

[12] Lalitha, K., Vargheese, C.M. and Balasubramanian, N., (1993) Spectrophotometric determination of Mimosine and e-hydroxy-4-(1H)-pyridone-the toxic principles of Leucaena leucocephala. Analytical Biochemistry, 213(1), 57-62.

[13] ICH-Q2A, (1994) Text on validation of analytical procedures. Proceedings of the International Conference on Harmonization of Technical Requirements for Registration of Pharmaceuticals for Human Use, Geneva.

[14] ICH-Q2B, (1996) Validation of analytical procedure: Methodology. Proceedings of the International Conference on Harmonization of Technical Requirements for Registration of Pharmaceuticals for Human Use, Geneva. 